\title{
Hydrus's-1D capability for assessment of soils water regime
}

\section{Y. Dmytruk, V. Zakharovskyi}

Yu. Fed'kovych Chernivtsi national university, Chernivtsi, Ukraine

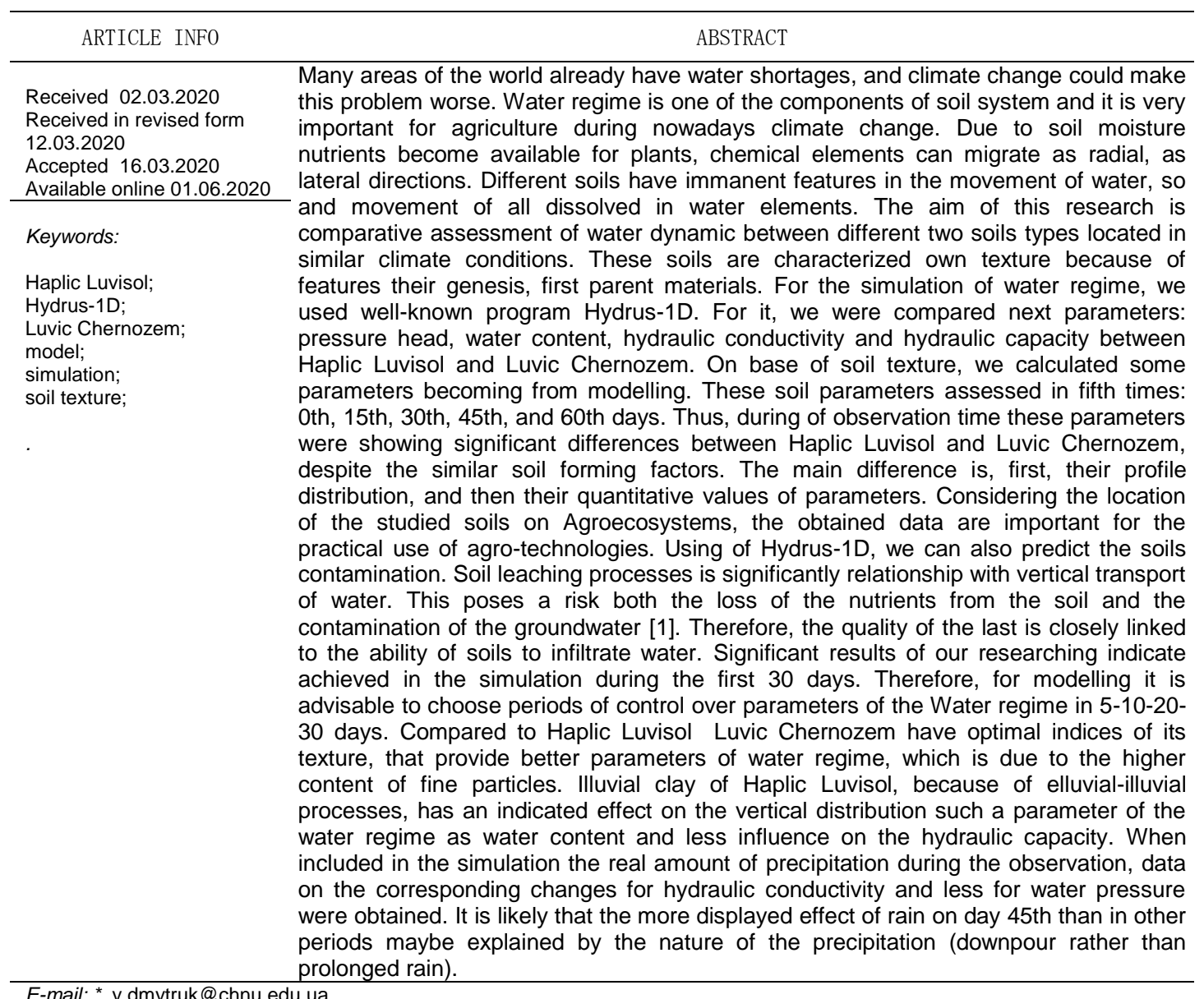

Citing: Dmytruk Y., Zakharovskyi V. 2020. Hydrus's-1D capability for assessment of soils water regime. Agrochemistry and Soil Science. Collected papers. No. 89. Kharkiv: NSC ISSAR. P. 18-27. DOI: https://doi.org/10.31073/acss89-02

\section{References}

1. Tsapko Y., Desyatnik K., Dmytruk Y. 2014. Assessment of changes of some functions of Ukrainian acid soils after chemical amelioration. Soil Science Annual. Vol. 65. (3). P. 111-117. DOI: https://doi.org/10.1515/ssa-2015-0002.

2. Global climate Report - Annual, 2019. URL: https://www.ncdc.noaa.gov/sotc/global/201913
3. FAO's work on climate change. United Nations Climate Change Conference. 2019. URL: http://www.fao.org/3/ca7126en/CA7126EN.pdf.

4. Šimunek J., Šejna M., Saito H., Sakai M., Van Genuchten M.Th. 2009. The HYDRUS-1D software package for simulating the onedimensional movement of water, heat, and multiple solutes in variably-saturated media, version 4.08. Department of Environmental Sciences. University of California. HYDRUS Software Series 3. Riverside. 330 p. URL: https://www.pcprogress.com/Downloads/Pgm_hydrus1D/HYDRUS1D-4.08.pdf.

5. Šimunek J., Van Genuchten M.Th., Šejna M. 2012. HYDRUS: Model use, calibration, and validation. Transactions of the ASABE. American society of Agricultural Engineers. Vol. 55(4). P. 1263-1274. DOI: https://doi.org /10.13031/2013.42239.

6. Chen M., Willgoose G., Saco P. 2014. Spatial prediction of temporal soil moisture dynamics using HYDRUS-1D. Hydrological Processes. Vol. 28(2). P. 171-185. DOI: https://doi.org/10.1002/hyp.9518.

7. Porn L., Yan B., Soun S., Ouk S. 2019. Effects of Loess Cavity on Soil Moisture Movement: Revealed by Soil Column and HYDRUS Model. Journal of Water Resource and Protection. Vol. 11(04). P. 371. DOI: https://doi.org/10.4236/jwarp.2019.114022.

8. Wang X., Li Y., Wang Y., Liu C. 2018. Performance of HYDRUS-1D for simulating water movement in water-repellent soils. Canadian journal of soil science. Vol. 98(3). P. 407-420. DOI: https://doi.org /10.1139/CJSS-2017-0116.

9. Minasny B., McBratney A. 2018. Limited effect of organic matter on soil available water capacity. European journal of soil science. Vol. 69(1). P. 39-47. DOI: https://doi.org/10.1111/ejss.12475.

10. Wu Y., Yang A., Zhao Y [et al.]. 2019. Simulation of soil water movement under biochar application based on the Hydrus-1D the black soil region of China. Applied ecology and environmental research. 2019. Vol. 17(2). P. 4183-4192. DOI: https://doi.org /10.15666/aeer/1702_41834192.

11. DSTU 4287:2004 Soil quality. Sampling (with abolition in Ukraine GOST 28168-89). (Ukr.).

12. DSTU 4730:2007 Soil quality. The soil granulometric composition analysis by pipette method in modification of N.A.Kachynskyi. [Existing from 2008-10-01]. Kyiv: State Committee of Ukraine for Technical Regulation and Consumer Policy. 2008.18 p. (Ukr.).

13. Kühn P., Aguilar J., Miedema R., Bronnikova M. 2018. Textural pedofeatures and related horizons. Interpretation of micromorphological features of soils and regoliths (Second Edition). P. 377-423. DOI: https://doi.org/10.1016/B978-0-444-531568.00011-8. 
14. Helevera O., Topolnyi F. 2018. Towards origin of podzolized and nonpodzolized acid soils. Ukrainian Journal of Ecology. Vol. 8(1). P. 516-526. DOI: https://doi.org /10.15421/2018 244. (Ukr.).

15. Jačka L., Pavlásek J., Kovář M. 2018. The effect of the layer interface on the distribution of infiltrated water in the profile of mountain podzol. In $20^{\text {th }}$ EGU General Assembly, EGU2018, Procedings from the conference held 4-13 April 2018 in Vienna Austria. Vol. 20. P. 13767. URL: https://ui.adsabs.harvard.edu/abs/2018EGUGA.2013767J/abstract.

16. Balasubramanian A. 2017. Soil Forming Processes. Technical Report. University of Mysore. 10 p. DOI: https://doi.org/10.13140/RG.2.2.34636.00644.

17. Génin J.M., Aïssa R., Gehin A., Abbelmoula M., Benali O., Ernstsen V., Ona-Nguena G., Upadhyay C., Ruby C. 2005. Fougerite and Fell-III hydroxycarbonate green rust; Ordering, deprotonation and/or cation substitution; Structure of hydrotalcite-like compounds and mythic ferrosichydroxide $\mathrm{Fe}(\mathrm{OH})_{(2+\mathrm{x})}$. Solid State Sciences. Vol. 7 P. 545-572. DOI: https://doi.org/ 10.1016/j.solidstatesciences.2005.02.001.

18. Mouhamad R., Atiyah A., Mohammad R., Iqbal M. 2015. Decomposition of organic matter under different soil textures. Current Vol. 1(1) P. 22-25. URL:

https://www.researchgate.net/publication/ 277775445_Decomposition_of_organic_matter_under_different_soil_textures.

19. Wang J., Huang Y., Long H. 2016. Water and salt movement in different soil textures under various negative irrigating pressures. Journal of integrative agriculture. Vol. 15(8). P. 1874-1882. DOI: https://doi.org/10.1016/S2095-3119(15)61209-6.

20. Belolipskyi V.O., Druhova O.P., Druhov O.N. 2019. Analysis of the soil hydrological function of steppe agrolandscapes: mathematical models of migration processes. Agrochemistry and Soil Science. Collected papers. No.88. NSC ISSAR. Kharkiv. P.12-21. DOI: https://doi.org/10.31073/acss88-02.

21. Van Genuchten M.Th. 1980. A closed-form equation for predicting the hydraulic conductivity of unsaturated soils 1 . Soil science society of America journal. Vol. 44(5) P. 892-898. DOI: https://doi.org/10.2136/sssaj1980.03615995004400050002x.

22. Hornberger G., Wiberg P., Raffensperger J., D’Odorico P. 2014. Elements of physical hydrology. Johns Hopkins University Press. Baltimore. 377 p. DOI: https://doi.org/10.2307/1468014

Удк 631.4: 502.3

\section{Можливості програми Hydrus-1D в оцінюванні водного режиму ґрунтів}

\section{Ю.М. Дмитрук, В.А. Захаровський}

Чернівецький національний університет ім. Ю.Федьковича, Чернівці, Україна

\begin{tabular}{l}
\multicolumn{1}{c}{ ІНФОРМАЦІЯ } \\
\hline Отримано 02.03.2020 \\
Отримано після \\
доопрацювання \\
12.03.2020 \\
Затверджено до друку \\
16.03.2020 \\
Доступно онлайн \\
01.06.2020 \\
\hline
\end{tabular}

Ключові слова:

Hydrus-1D;

гранулометричний склад; моделювання; сірий лісовий ґрунт; чорнозем опідзолений.

Проблема забезпечення прісною водою постає все гостріше, i її посилюють кліматичні зміни, які спостерігаються у світі. Зростання температур повітря спричинює істотні пертурбації, які зачіпають всі аспекти життя людей. Проте особливої гостроти ця проблема набуває для сфери агровиробництва. Важливість водного режиму ґрунтів, як одного з їх компонентів, пояснюється не тільки власне функціонуванням екосистеми як такої. Насамперед через ґрунтову вологу забезпечується живлення рослин, а також міграція хімічних елементів як в межах профілю (радіально), так і між ґрунтовими педонами (латерально). Апріорі зрозуміло, що різні ґрунти володіють іманентними особливостями водного режиму, який залежить від розміщення ґрунту в конкретних умовах (всі чинники ґрунтогенезу) та характеру ґрунтоутворення. Метою виконаного дослідження $є$ порівняльна оцінка водного режиму різних ґрунтів (сірий лісовий та чорнозем опідзолений), які просторово межують між собою, а тому немає підстав говорити про достовірну різницю кліматичних умов (температура повітря, кількість опадів, гідротермічний коефіцієнт). Проте різниця в материнських породах цих ґрунтів i, як наслідок, в кінцевому результаті генезису зумовила низку відмінностей за їх показниками, найперше - за гранулометричним складом. Саме останній є одним 3 основних чинників впливу на водний режим ґрунту, що власне й враховує програма Hydrus-1D. Ця програма широко використовується закордонними дослідниками, проте в Україні ще немає достатньої бази даних про результати такого моделювання. У процесі останнього нами оцінювалися такі параметри: тиск води, її вміст, гідравлічна провідність та гідравлічна ємність. У модель включено дані про грансклад генетичних горизонтів досліджуваних ґрунтів, на основі яких вказані вище параметри ґрунтів оцінювали: на початок моделювання, 15-й, 30-й, 45-й і 60-й дні від початку. Встановлено, що протягом періоду спостереження ці параметри істотно відрізняються для сірого лісового ґрунту і чорнозему опідзоленого, незважаючи на тотожні кліматичні показники. Причому виявлено, що різниця між ґрунтами більша щодо профрільного розподілу аналізованих параметрів, а потім вже за їх кількісними значеннями. Результати нашого дослідження демонструють істотну динаміку параметрів симуляції в процесі моделювання протягом перших 30 днів, а надалі різниця між ними практично нівелюється. Тому для моделювання такого характеру доцільно вибирати періоди контролю параметрів водного режиму через 5-10-20-30 днів. Показники гранскладу чорнозему опідзоленого (важчий гранулометричний склад завдяки більшому вмісту дрібнодисперсних часток,), забезпечують кращі параметри водного режиму, порівняно з сірим лісовим ґрунтом. Елювіально-ілювіальні процеси, які формували сірий лісовий ґрунт та призвели до утворення ілювіальних горизонтів з підвищеним, порівняно 3 іншими генетичними горизонтами вмістом мулу, істотно вплинули на вертикальний розподіл такого параметра водного режиму, як вміст води та менше на гідравлічну ємність. При включенні в моделювання реальної кількості опадів, які припали на час спостереження, одержано дані моделі щодо відповідних змін для гідравлічної провідності та менше для тиску води. Цілком ймовірно, що більш виражений ефект дощу на 45-й день, ніж в інші періоди, пояснюється характером опадів (зливи, а не тривалий помірний дощ). Отже, дані, одержані нами в процесі симуляції, зважаючи на розміщення ґрунтів в агроекосистемах, можуть застосовуватися для впровадження конкретних агротехнологій та оцінювання їхніх результатів. Зокрема, є можливості передбачення інтенсивності процесів вилуговування, які істотно залежать від вертикального переносу води. Результатом $є$ ризики як втрати поживних речовин 3 _ ґрунту, так і забруднення підґрунтових вод. Використання Hydrus 1D дає змогу 
прогнозувати забруднення ґрунтів, що надважливо для організації дієвого моніторингу

стану ґрунтового покриву і ареалів антропогенних імпактів.

*E-mail: y.dmytruk@chnu.edu.ua

Форма цитування: Dmytruk Y., Zakharovskyi V. Hydrus's-1D capability for assessment of soils water regime. Agrochemistry and Soil Science. Collected papers. No. 89. Kharkiv: NSC ISSAR. 2020. P. 18-27. DOI: https://doi.org/10.31073/acss89-02

УДК 631.4: 502.3

\title{
Возможности программы Hydrus-1D в оценке водного режима почв
}

\author{
Ю.М. Дмитрук, В.А. Захаровский
}

Черновицкий национальный университет им. Ю.Федьковича, Черновцы, Украина

E-mail:y.dmytruk@chnu.edu.ua

Проблема обеспечения пресной водой становится все более острой и усиливается в свете климатических изменений, наблюдаемых в мире. Рост температуры воздуха вызывает существенные возмущения, которые затрагивают все аспекты жизни людей. Однако особую остроту эта проблема приобретает в сельскохозяйственном производстве. Важность водного режима почв как одного из их компонентов объясняется не только функционированием экосистемы как таковой. В первую очередь за счет влажности почвы обеспечивается питание растений, а также миграция химических элементов как внутри профиля (радиально), так и между педонами (латерально). Априори ясно, что различные почвы имеют имманентные особенности водного режима, который зависит от размещения почвы в конкретных условиях (все фракторы почвообразования) и характера формирования почвы. Целью исследования является сравнительная оценка водного режима различных почв (серая лесная и чернозем оподзоленный), которые пространственно граничат друг с другом, и поэтому нет оснований говорить о достоверном различии климатических условий (температура, количество осадков, гидротермический коэффициент). Однако разница в материнских породах и, как следствие, разница в конечном результате генезиса, обусловила ряд различий в их свойствах, в первую очередь - по гранулометрическому составу. Последний является одним из основных факторов, влияющих на водный режим почвы, что, собственно, и учитывается программой Hydrus-1D. Данная программа широко используется иностранными исследователями, но в Украине пока нет достаточной базы данных по результатам такого моделирования. В ходе последнего мы оценивали следующие параметры: давление воды, ее содержание, гидравлическую проводимость и гидравлическую емкость. Модель включает данные о грансоставе генетических горизонтов исследованных почв, на основе которых оцениваются вышеуказанные параметры почвы: в начале моделирования, 15-й, 30-й, 45-й и 60-й дни от начала. Установлено, что в период наблюдения эти параметры существенно различаются для серой лесной почвы и чернозема, несмотря на идентичные климатические показатели. Кроме того, было установлено, что разница между почвами больше по отношению к профильному распределению проанализированных параметров, а затем уже по их значениям. Результаты нашего исследования показывают значительную динамику моделируемых параметров в течение первых 30 дней, а позже разница между ними практически выравнивается. Поэтому для моделирования такого типа желательно выбрать периоды контроля параметров водного режима в 5-10-20-30 дней. Качество грансостава чернозема оподзоленного (более высокое содержание мелкодисперсных частиц) обеспечивает лучшие параметры водного режима по сравнению с серой лесной почвой. Элювиально-иллювиальные процессы, которые образовали серую лесную почву и привели к образованию иллювиальных горизонтов с увеличенным, по сравнению с другими генетическими горизонтами содержанием ила, существенно повлияли на вертикальное распределение такого параметра водного режима, как содержание воды и меньше - на гидравлическую емкость. При включении в моделирование реального количества осадков в период наблюдения получили данные относительно соответствующих изменений для гидравлической проводимости и давления воды. Вполне вероятно, что более выраженный эффект дождя на 45-й день, чем в другие периоды объясняется характером осадков (ливни, а не длительный умеренный дождь). Следовательно, данные, полученные нами в процессе моделирования, с учетом размещения почв в агроэкосистемах, могут быть использованы для внедрения конкретных сельскохозяйственных технологий и оценки их результатов. В частности, можно прогнозировать интенсивность процессов выщелачивания, которые в значительной степени зависят от вертикального переноса воды. Результатом является риск как потери питательных веществ из почвы, так и загрязнения грунтовых вод. Использование Hydrus 1D позволяет прогнозировать загрязнение почвы, что очень важно для организации эффективного мониторинга почвенного покрова и антропогенных зон воздействия.

Ключевые слова: Hydrus-1D; гранулометрический состав; моделирование; серая лесная почва; чернозем оподзоленный. 